\title{
Toxicity of hair dyes in human keratinocytes Effects of Basic Yellow 57 in combination with Resorcinol and Hydrogen Peroxide
}

\author{
C. van Gorp \\ Faculty of Health, Medicine and Life Sciences \\ Maastricht University \\ charlotte.vangorp@student.maastrichtuniversity.nl
}

\begin{abstract}
Background. In the United States and Europe, more than 30\% of women over 18 years and approximately $10 \%$ of men over 40 years are using hair colouring products. Previous studies have shown that low concentrations of the semi-permanent hair dye Basic Yellow 57 (BY57) lead to toxicity in human keratinocytes. The aim of this study is to investigate the DNA damaging effects of $\mathrm{BY}_{57}$ in combination with other (oxidizing) components, such as hydrogen peroxide (a bleach component) and resorcinol (a colour coupler) in human keratinocyte ( $\mathrm{HaCaT}$ ) cells. Furthermore, another aim of the present study is to evaluate the potential DNA damaging mechanisms caused by these hair dye components.

Methods. The HaCaT cells were exposed to different concentrations BY 57 (o-10o $\mu \mathrm{g} / \mathrm{ml})$, hydrogen peroxide $(0-100 \mu \mathrm{M})$, resorcinol $(0-100 \mu \mathrm{g} / \mathrm{ml})$ and to the possible combinations of these components. Diphenyleneiodonium (DPI; 10 and $50 \mu \mathrm{g} / \mathrm{ml}$ ) and hydroxyurea $(\mathrm{HU} ; 10 \mathrm{mM})$ were added to the keratinocytes to evaluate the potential DNA damaging mechanisms. DPI was applied as an NADPH oxidase inhibitor and HU functions as an DNA polymerase inhibitor. In the present study, the tested concentrations are based on the proportion of the hair dye components as present in commercially available hair dye products. In order to detect potential DNA fragmentation after treating the cells with the different hair dye components, the single cell gel electrophoresis (comet) assay was used. Results. Treatment of the HaCaT cells with hydrogen peroxide $(100 \mu \mathrm{M})$ and Basic Yellow 57 $(100 \mu \mathrm{g} / \mathrm{ml})$ lead to a significant induction of DNA fragmentation in human keratinocytes. The combination of $\mathrm{BY}_{57}$ together with hydrogen peroxide and resorcinol lead to a significant induction in DNA damage. However, this induction was approximately equal to
\end{abstract}


the DNA damaging effects caused by hydrogen peroxide only. Furthermore, the addition of DPI lead to an unexpected induction of DNA fragmentation.

Conclusion. The present results showed that the exposure of human keratinocytes to Basic Yellow 57, hydrogen peroxide and the combination treatments of the hair dye components containing hydrogen peroxide lead to an induction of DNA fragmentation. However, the possible working mechanisms of DNA damaging effects caused by BY 57 remains unclear. The DNA damaging effects of DPI could suggest an inhibition of the DNA repair system via the inhibition of NADPH oxidase. Since this effect is not confirmed by the results of the DNA repair inhibitor $(\mathrm{HU})$, no conclusion could be drawn from these findings. To elucidate the possible DNA damaging mechanisms of $\mathrm{BY}_{57}$ on human keratinocytes, further research is needed.

\section{Keywords}

Basic Yellow 57, Resorcinol, Hydrogen Peroxide, HaCaT cells, Comet assay, DNA damage, DPI, HU.

\section{Introduction}

Many people in the United States and Europe use hair dyes, more than one-third of women over 18 years and approximately $10 \%$ of men over 40 years are using hair colouring products. When using hair colouring products, it is important to know whether exposure to hair colouring products have health risks (1). There are different types of hair colouring products, e.g. permanent and semi-permanent hair dyes which make up approximately $80 \%$ of the currently market products. Permanent hair dyes penetrate inside the hair shaft. These hair dyes contain chemicals (e.g. ammonia) and hair dye couplers (e.g. resorcinol), which have an interaction with oxidative components (e.g. hydrogen peroxide) to form the pigment molecules. In contrast, semi-permanent hair dyes are non-oxidative and do not or partially penetrate into the hair shaft. Therefore, the hair colouring effects of permanent hair colouring products will remain longer in contrast to semi-permanent hair colouring products $(1,2)$.

There are some concerns about the harmful effects of hair colouring products, since 5000 different chemicals are used in these products. In addition, the oxidative stress potential of permanent and semi-permanent hair dyes have been investigated. Basic Yellow 57, which is a component applied in semi-permanent hair dye formulations, did not lead to radical formation. However, intracellular reactive oxygen species (ROS) measurements revealed increased levels of ROS inside human skin cells. In addition, Basic Yellow 57 was able to induce DNA oxidation as measured by the 8-oxo-G levels in human keratinocytes and 
therefore some DNA damaging effects were indicated [Thalita Boldrin Zanoni, Personal communication]. Thus, the application of BY 57 may lead to toxicity and DNA damaging effects in human keratinocytes.

Since the interaction of Basic Yellow 57 with other (oxidizing) hair dye components has not been investigated yet, the present study has focussed on the DNA damaging effects of these interactions. Below, a short description will be given of the investigated components.

\section{Basic Yellow 57 and Hydrogen Peroxide}

Basic Yellow 57 (BY57) is a synthetic, semi-permanent hair dye colour and is applied in direct hair colouring products. The Scientific Committee on Consumer Safety (SCCS) evaluated whether Basic Yellow 57, in non-oxidative hair dye formulations, is safe with a certain exposure concentration on the scalp. The final concentration of BY 57 applied in direct hair dye formulations is $2.0 \%$ (4). $\mathrm{BY}_{57}$ is a mixture containing $63.5 \%$ dye, $9.6 \%$ sugar, $6.9 \%$ volatile matter and $20 \%$ inorganic salts (chloride, sulphate etc.) (5). The SCCS assumed that Basic Yellow 57 is used without combining it with oxidising agents (e.g. hydrogen peroxide) (4). However, in commercially available hair colouring products, Basic Yellow 57 is used in combination with hydrogen peroxide. In addition, hydrogen peroxide is indicated as an ingredient suspected to cause skin or organ toxicity, therefore this product has been banned for use in cosmetics in Canada. In contrast, hydrogen peroxide has many physiological functions in the human body. For example, hydrogen peroxide is able to activate immune cells and lead to vascular remodelling $(6,7)$. The concentration hydrogen peroxide applied in hair dyes varies and differs between different sources. In conventional hair dyes, the range of applied hydrogen peroxide varies from $3 \%$ up to $12 \%$ $(8,9)$. Since some hair colouring products contain percentages of hydrogen peroxide up to $12 \%$, hydrogen can cause harmful effects after the application on the human skin. Finally, the SCCS stated that the use of Basic Yellow 57 is without a risk to the consumer, assuming that $\mathrm{BY}_{57}$ is used in non-oxidative hair dye formulations $(4,5)$.

\section{Resorcinol}

Resorcinol is a phenol derivative in which a hydrogen atom is substituted by a hydroxyl group. This chemical is present in natural products, such as broad bean, peels and is a component of tobacco smoke. Furthermore, resorcinol is used in the production of different kind of mechanical goods, is a chemical intermediate for the manufacture of chemicals and is present in creams and lotions (10). In oxidative hair dyes, the amount of resorcinol is around $5 \%$ or even lower, in practice the free resorcinol level is limited to $1.25 \%$. Resorcinol is used in pharmaceutical preparations for the treatment of different skin 
conditions (e.g. acne, eczema, psoriasis) $(10,11)$. The SCCS stated that resorcinol is used in oxidative hair colouring products with a maximum concentration of $2.5 \%$, but with a final concentration of $1.25 \%$ after mixing it in a 1:1 ratio with hydrogen peroxide. Application of resorcinol in hair dye formulations (3-25\% resorcinol) could cause local hyperaemia, dermatitis, loss of the upper layers of the skin and in severe cases enlargement of local lymph nodes. In addition, others stated that resorcinol was not able to induce DNA strand breaks and mutations (in vitro and in vivo) (12).

The aim of this study is to investigate the DNA damaging effects of Basic Yellow 57 (BY57) in combination with hydrogen peroxide and resorcinol in human keratinocyte ( $\mathrm{HaCaT}$ ) cells in vitro by using the single cell gel electrophoresis (comet) assay. This assay is able to measure single and double strand breaks in the DNA after exposure of cells to different treatments. Since the SCCS stated that semi-permanent hair colouring products are not used together with oxidizing products, the interaction between these components has not been investigated yet. As mentioned in the beginning, previous studies have shown that low concentrations of the semi-permanent hair dye Basic Yellow 57 (BY 57 ) lead to toxicity in human keratinocytes in contradiction to the findings published by the SCCS. In the present study, the tested concentrations are based on the proportion of the hair dye components as present in commercially available hair dye products. Since it is expected that potential DNA damage induced by these hair dye components can be due to NADPH oxidase generated reactive oxygen species (ROS), an NADPH oxidase inhibitor will be used to evaluate the potential mechanisms involved in DNA damaging effects of BY 57 and combinations with hydrogen peroxide and resorcinol.

\section{Material and methods}

\section{Cell culture}

For in vitro evaluation of toxic effects of hair dye components, the HaCaT cell line was used. $\mathrm{HaCaT}$ cells are in vitro spontaneously transformed, immortalized keratinocytes derived from histologically normal skin. These human keratinocytes were cultured in DMEM medium containing 4.5 g/L D-glucose and $25 \mathrm{mM}$ Hepes (Gibco, UK), supplemented with $50 \mu \mathrm{g} / \mathrm{mL}$ penicillin (Gibco, UK), $50 \mathrm{\mu g} / \mathrm{ml}$ streptomycin (Gibco, UK) and 10\% of Foetal Calf Serum (Gibco, UK). The cell culture was incubated at $37^{\circ} \mathrm{C}$ in $5 \% \mathrm{CO}_{2}$ in air.

\section{Treatments of human keratinocytes}

The human keratinocytes (HaCaT cells) were seeded into 12- or 24-well culture plates at a density of $1 \times 10^{5}-2.5 \times 10^{5}$ cells per well by using the Bürker counting chamber. Furthermore, 
the cells grown at $37^{\circ} \mathrm{C}$ in $5 \% \mathrm{CO}_{2}$ in a tissue culture incubator for approximately two days until 80-90\% confluent monolayers were obtained. After washing the cells with HBSS, the human skin cells were incubated with various concentrations $\mathrm{H}_{2} \mathrm{O}_{2}(\mathrm{O}-160 \mu \mathrm{M})$, resorcinol (o-100 $\mu \mathrm{g} / \mathrm{ml}), \mathrm{BY}_{57}(\mathrm{O}-100 \mu \mathrm{g} / \mathrm{ml})$ and the possible combinations of these components at $37^{\circ} \mathrm{C}$ for 30 minutes. The concentrations of these components were calculated based on penetration studies which have measured the percentages of the hair dye components that are able to penetrate through the skin layers in vitro (BY $57: 2.44 \%$; resorcinol: $0.4 \%$ ) $(1,5)$. Furthermore, the hair dye components were also tested in the proportions as found in commercially available hair dye products $\left(2 \% \mathrm{BY} 57 ; 1.25 \%\right.$ and $\left.5 \% \mathrm{H}_{2} \mathrm{O}_{2}\right)$ and were diluted 100,1000 and 10.000 times based on calculated dilutions of the components as present in the underlying skin layers. In order the evaluate the mechanisms of the potential DNA damaging effects of the hair dye components, the keratinocytes were exposed to DPI (10 and $50 \mu \mathrm{M})$ and $\mathrm{HU}(10 \mathrm{mM})$ and in combination with $\mathrm{BY} 57$, resorcinol and $\mathrm{H}_{2} \mathrm{O}_{2}$. All the components and their combinations as well as the combinations with DPI and $\mathrm{HU}$ were mixed and diluted in DMEM without Foetal Calf Serum (FCS) before adding to the keratinocytes. DPI was used as an NADPH oxidase inhibitor which has frequently been used to inhibit the production of reactive oxygen species (ROS) (13). In order to inhibit the DNA repair system in the $\mathrm{HaCaT}$ cells, hydroxyurea $(\mathrm{HU})$ was used as a ribonucleotide reductase inhibitor and inhibits the production of deoxyribonucleotides needed for DNA synthesis (14). Since deoxyribonucleotides are necessary for the polymerization of DNA strands after DNA repair, hydroxyurea will prevent the resynthesis of DNA strands. After incubation, cells were washed with HBSS and subsequently incubated with 400$500 \mu \mathrm{l} /$ well trypsin to detach the cells for $2-3$ minutes at $37^{\circ} \mathrm{C}$. After trypsinization, PBS (0.4-0.5 ml/well; pH 7.4) was added to resuspend the cells. The cells were transferred into eppendorfs and centrifuged for 5 minutes at $3000 \mathrm{rpm}$. Next, the supernatant was removed of the cell pellet and the cells were stored in a fridge until processing for the single cell gel electrophoresis.

\section{The single-cell gel electrophoresis (comet) assay}

The single cell gel electrophoresis assay was essentially the same as described by Singh et al. (1988). Briefly, after treating the cells with different treatments, the cell pellet was suspended with $100 \mu \mathrm{l}$ of $1 \%$ low-melting-point (LMP) agarose of $37^{\circ} \mathrm{C}$ and layered onto superfrosted glass microscope slides pre-coated with normal-melting-point agarose. The slides were covered with a coverslip and stored at $4{ }^{\circ} \mathrm{C}$ for 5-10 minutes to solidify the lowmelting-point agarose. In addition, the coverslips were removed and the slides were placed into slide holders containing cold lysis solution (2.5 M NaCl, $100 \mathrm{mM}$ EDTA, $10 \mathrm{mM}$ Tris [pH 
10.0], and $1 \%$ Triton $\mathrm{X}-100$ and $10 \%$ dimethyl sulfoxide) to remove the cellular proteins and then was stored for 1-3 days at $4^{\circ} \mathrm{C}$. To unwind the DNA, the slides were placed into an ice-cold electropheresis tank containing fresh alkaline electrophoresis buffer $(300 \mathrm{mM}$ $\mathrm{NaOH}$ and $1 \mathrm{mM}$ EDTA [pH minimum of 12]) for 20 minutes at $4^{\circ} \mathrm{C}$. The electrophoresis was performed at $25 \mathrm{~V}$ and $300 \mathrm{~mA}$ under the same conditions as mentioned above. After electrophoresis, the slides were washed three times for 5 minutes with cold neutralisation buffer (0.4 M Tris [pH 7.5]) and subsequently rinsed three times for 5 minutes with cold $100 \%$ ethanol. Next, the slides were stored at $4^{\circ} \mathrm{C}$ until analysis of the slides for further analysis. All these steps were performed under dim light to prevent additional DNA damage. For microscopic analysis, $50 \mu$ l ethidium bromide $(10 \mu \mathrm{g} / \mathrm{ml})$ was added to each slide and 50 randomly selected cells were analysed from each sample. For the analysis of the slides, all the slides were coded and scored blind. A fluorescence microscope and the Comet Assay III software (Perceptive Instruments, Suffolk, UK) were used for the analysis of the different samples. The DNA damage was measured as tail moment, based on the product of the percentage of DNA in the tail and tail length (figure 4). The mean and SEM of the median of the tail moment were calculated for each sample. Since data showed a non-normal distribution, the median of the tail moment was used for processing the data.

\section{Statistical analysis}

The results are presented as mean \pm standard error of mean (mean \pm SEM). The data provided by using the comet assay were analysed using the ANOVA test and the bonferroni post hoc test. The statistical significance was defined as $p<0.05$ for all tests. Statistical analyses were analysed with SPSS for Windows (version 19.0; SPSS, Inc, Chicago, IL).

\section{Results}

\section{The DNA damaging effects of Basic Yellow 57, resorcinol and hydrogen peroxide}

First, the DNA damaging effects of the single hair dye components were assessed using the Comet assay. Before studying the potential DNA damaging effects of the combination of these components, it is important to detect which concentration of each component is useful for testing these combinations. With regard to hydrogen peroxide, treatments of keratinocytes with $100 \mathrm{MM} \mathrm{H}_{2} \mathrm{O}_{2}$ increased DNA strand break formation in contrast to the other tested concentrations (not shown in figure). Basic Yellow 57 (10, 50 and $100 \mu \mathrm{g}$ / $\mathrm{ml} \mathrm{BY} 57$ ) increased the induction of DNA damage relatively to the untreated cells (not shown in figure). In contrast, all the tested concentrations resorcinol did not induce DNA damage (not shown in figure). After the hair dye components concentrations of $100 \mu \mathrm{M}$ 
were replicated in 6-fold, hydrogen peroxide and BY 57 significantly $(p<0.0001$ and $p<$ 0.05) increased the induction of DNA fragmentation (figure 1).

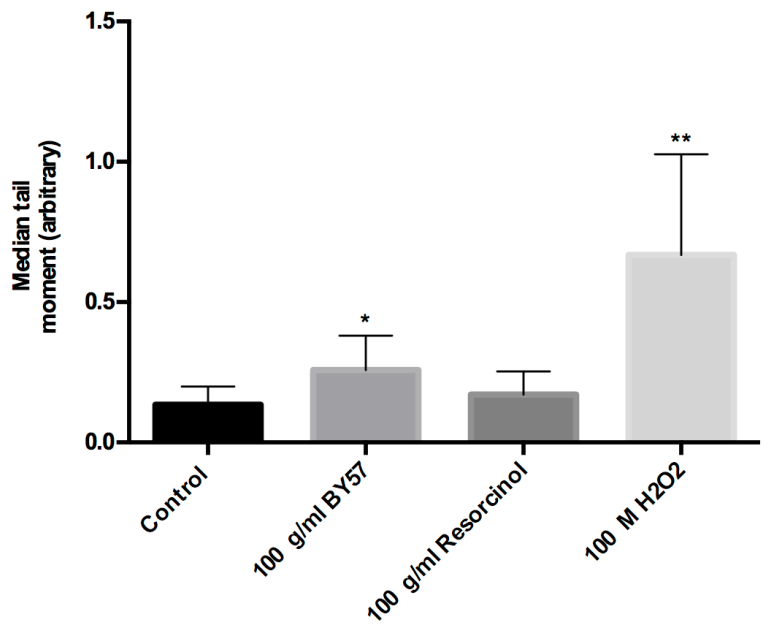

Figure 1. DNA damage indicated by the median of the tail moment in human keratinocytes after 30 minutes exposure to the highest tested concentrations of $\mathrm{H}_{2} \mathrm{O}_{2}(n=10), \mathrm{BY} 57(n=5)$ and resorcinol $(n=5)$ compared to the control $(n=10)$. The values are expressed as mean \pm SEM. ${ }^{*} p<0.05 ;{ }^{* *} p<0.0001$ denotes a significant difference from control values. $\mathrm{BY}_{57}=$ Basic Yellow $57 ; \mathrm{H}_{2} \mathrm{O}_{2}=$ hydrogen peroxide

The DNA damaging effects of the combination Basic Yellow 57, resorcinol and hydrogen peroxide

Subsequently, to evaluate the DNA damaging effects of the combination of the hair dye components, $\mathrm{BY}_{57}$ was tested in combination with resorcinol and hydrogen peroxide (figure 2). The treatment with only hydrogen peroxide as well as the combinations that contain hydrogen peroxide significantly increased the induction of DNA damage ( $p$ $<0.01$ or $p<0.05$ ) relatively to the untreated cells, $\mathrm{BY}_{57}$ and resorcinol. In contrast, the combinations with $\mathrm{BY}_{57}$, resorcinol or both did not lead to an increased induction in DNA damage relatively to the control cells (figure $\mathbf{2 A}$ ). 

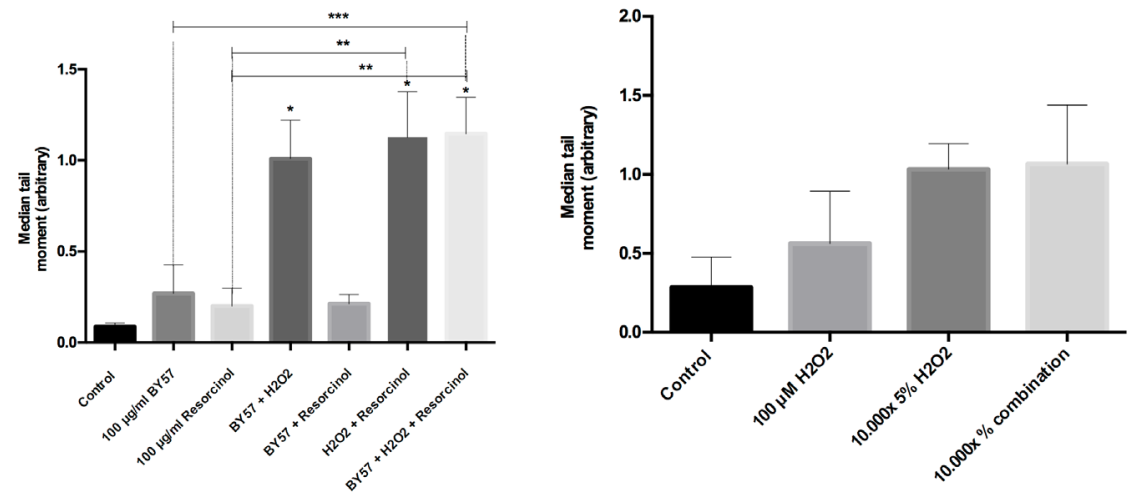

Figure 2. DNA damage indicated by the median of the tail moment in human keratinocytes after 30 minutes exposure to the combinations of $\mathrm{BY}_{57}$, resorcinol and hydrogen peroxide. (A) Exposure to control (non-treated cells) and the tested combinations of $\mathrm{BY} 57(100 \mu \mathrm{g} / \mathrm{ml})$ with resorcinol $(100 \mu \mathrm{g} / \mathrm{ml})$ and hydrogen peroxide $(100$ $\mu M)$. All these treatments are performed in triplicate. (B) Exposure to control $(n=6), 100 \mu M$ hydrogen peroxide $(n=3), 5 \%$ hydrogen peroxide 10.000 times diluted $(n=6)$ and combinations of the components indicated as percentages. \% combination $(n=6)$ consists of $2 \% B_{57}(5.4 \mu M), 1.25 \%$ resorcinol $(11.3 \mu M)$ and $5 \%$ hydrogen $(160 \mu M)$ peroxide and is 10.000 times diluted. The values are displayed as mean \pm SEM. ${ }^{*} p<0.01$ significantly different from control values. ${ }^{* *} p<0.01 ;{ }^{* * *} p<0.05$ denotes a significant difference between combinations as indicated in the figure. $\mathrm{BY}_{57}=$ Basic Yellow $57 ; \mathrm{H}_{2} \mathrm{O}_{2}=$ hydrogen peroxide.

The proportions of the hair dye components as found in commercially available hair dye components are displayed in figure $\mathbf{2} \mathbf{B}$. Only the 10.000 times dilution is displayed in this figure because the 100 and 1000 times diluted combinations gave too much damage and were therefore not measurable. The $100 \mathrm{MM} \mathrm{H}_{2} \mathrm{O}_{2}, 10.000$ times diluted $5 \% \mathrm{H}_{2} \mathrm{O}_{2}(160$ $\mu \mathrm{M} \mathrm{H}_{2} \mathrm{O}_{2}$ ) and \% combination did all increase the induction in DNA damage relatively to the untreated cells. The level of DNA damage between $5 \% \mathrm{H}_{2} \mathrm{O}_{2}$ and \% combination, both 10.000 times diluted, are approximately equal (figure 2B).

\section{The DNA damaging effects of a NADPH oxidase inhibitor in combination with the hair dye components}

To elucidate the possible mechanisms of $\mathrm{BY} 57$ and hydrogen peroxide induced DNA damage, diphenyleneiodonium (DPI) was used as an NADPH oxidase inhibitor to determine whether this damage is caused by NADPH oxidase generated reactive oxygen species (ROS) (figure 3). The $100 \mu \mathrm{g} / \mathrm{ml}$ Basic Yellow 57 did induce the level of DNA damage in keratinocytes (figure 1) and was therefore used for evaluating the mechanisms behind this effect. Each treatment increased the DNA fragmentation relatively to the untreated cells. DPI $(50 \mu \mathrm{M})$ itself induced the DNA strand break formation as well as the combinations that contain DPI (figure 3). 


\section{The DNA damaging effects of DPI in comparison with a DNA repair inhibitor}

To determine whether the induced DNA fragmentation could be caused by inhibition of the DNA repair system, hydroxyurea (HU), a DNA repair inhibitor, was added to the skin cells. In addition, the cells were exposed to a lower DPI concentration (10 $\mu \mathrm{M})$ as well, to determine whether the DNA damaging effects of DPI is dose-dependent (figure 3). BY 57 in combination with $50 \mu \mathrm{M}$ DPI lead to a significant induction $(p<0.05)$ of DNA fragmentation relatively to the control as well as relatively to $\mathrm{BY}_{57}$ only. Furthermore, the DNA fragmentation levels cause by $10 \mu \mathrm{M}$ DPI is lower in comparison with $50 \mu \mathrm{M}$ DPI

\section{(figure 3).}

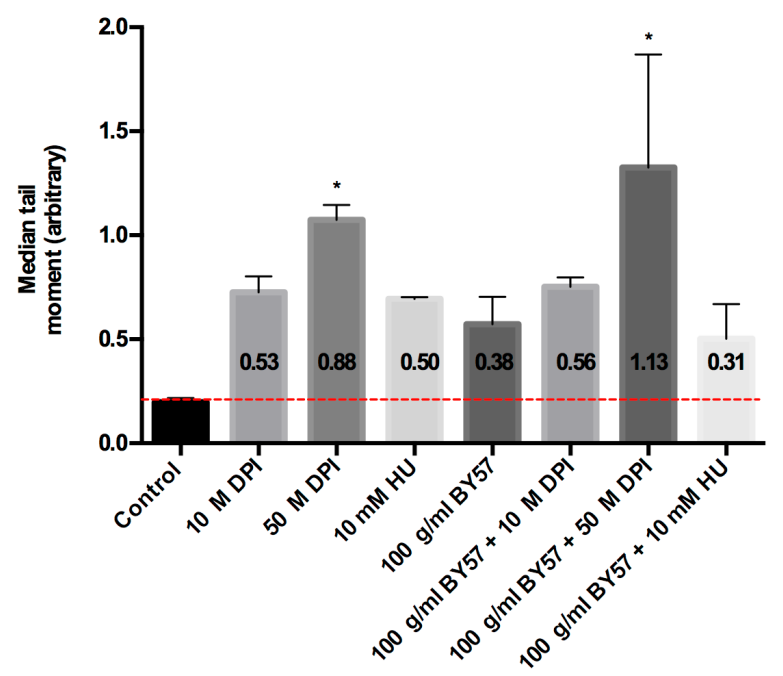

Figure 3. DNA damage indicated by the median of the tail moment in human keratinocytes after 30 minutes exposure to $50 \mu \mathrm{M} \mathrm{DPI}, 10 \mu \mathrm{M} \mathrm{DPI}, 10 \mathrm{mM} \mathrm{HU}$ and the possible combinations with $\mathrm{BY}_{57}$. All the treatments were performed in triplicate. The upper part of the bars, above the red dotted line, indicates the DNA damaging effects of the different treatments relatively to the control values. These relative values are displayed in the bars as well. The values are expressed as mean \pm SEM. ${ }^{*} p<0.01$ denotes a significant difference from control values. $\mathrm{BY}_{57}=$ Basic Yellow $57 ; \mathrm{H}_{2} \mathrm{O}_{2}=$ hydrogen peroxide; $\mathrm{DPI}=$ diphenyleneiodonium; $\mathrm{HU}=$ hydroxyurea.

The relative values of each treatment were displayed to determine whether an induction of DNA damage was caused by the sum of two separate treatments or an additional effect.

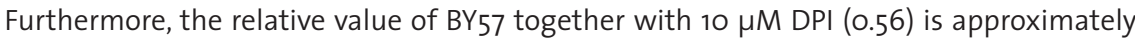
equal to $10 \mu \mathrm{M}$ DPI only. The same applies for BY 57 in combination with $50 \mu \mathrm{M} \mathrm{DPI}$ and 
$10 \mathrm{mM} \mathrm{HU}$, these relative values are approximately equal to $50 \mu \mathrm{M} \mathrm{DPI}$ and $10 \mathrm{mM} \mathrm{HU}$ separately. Moreover, the induction in DNA fragmentation caused by $50 \mu \mathrm{M} \mathrm{DPI}$ is higher in comparison with the DNA fragmentation level of $10 \mathrm{mM} \mathrm{HU}$ (figure 3).

\section{Discussion}

\section{The potential DNA damaging effects of the hair dye components}

Based on the results, resorcinol itself did not lead to the induction of DNA fragmentations and in combination with hydrogen peroxide and $\mathrm{BY}_{57}$. This finding exclude the potential DNA damaging effects of resorcinol present in hair dye formulations. As expected, hydrogen peroxide itself and in combination with resorcinol and $\mathrm{BY}_{57}$ lead to an induction of DNA fragmentation. Hydrogen peroxide showed an additional DNA damaging effect together with DPI in comparison with only DPI. DPI functions as an NADPH oxidase inhibitor, thus it can be excluded that hydrogen peroxide causes DNA fragmentation via NADPH oxidase. Since mitochondrial respiration is a major source of cellular ROS, it was suggested that the source of the DNA damage caused by hydrogen peroxide could be induced via mitochondrial ROS. However, several studies indicated that DPI is also an inhibitor of mitochondrial ROS production at concentrations that inhibit NADPH oxidase and therefore reduce the production of superoxide caused by mitochondrial respiration $(13,16)$. This finding suggests that hydrogen peroxide has a direct DNA damaging effect $(6,7)$. The potential mechanisms of the remarkable DNA damaging effects of DPI will be explained below.

The exposure of human keratinocytes to $100 \mu \mathrm{g} / \mathrm{ml} \mathrm{BY} 57$ significantly increased the induction in DNA strand breaks. Since a previous study showed that low concentrations of BY $57(40$ and $80 \mu \mathrm{g} / \mathrm{ml})$ induced the intracellular levels of reactive oxygen species (ROS) in human keratinocytes, the source of the potential DNA damaging effects is likely to be these ROS [Thalita Boldrin Zanoni, Personal communication]. This is the reason why addition of antioxidants will not reveal the mechanism of the inducible damage caused by BY 57 . Therefore, an NADPH oxidase inhibitor, diphenyleneiodonium (DPI), was added to the skin cells to investigate whether the ROS was derived from NADPH oxidase. In contrast to the expectations, the addition of DPI $(50 \mu \mathrm{M})$ as well as the addition of $\mathrm{BY}_{57}$ in combination with DPI lead to a significant increase in DNA damage in the human keratinocytes instead of a reduction of the BY 57 induced DNA damage. These findings indicated that DPI is responsible for the induction of DNA fragmentation instead of the expected reduction.

With regard to the relative values, the induction of DNA fragmentations is probably due to the effects of DPI, whereas the induction in DNA strand breaks by BY 57 only was not 
detectable anymore. The same effects were detected when the human keratinocytes were exposed to a lower concentration of DPI $(10 \mu \mathrm{M})$ in combination with $\mathrm{BY}_{57}$ compared to BY57 only (figure 3).

The potential working mechanisms of NADPH oxidase, DPI and HU in the DNA damaging effects of $\mathrm{BY}_{57}$

A possible explanation for the induction of the DNA damage is the inhibition of a DNA repair mechanism by DPI. Apurinic/apyrimidinic endonuclease1/redox factor-1 (APE1/Ref1) is a protein involved in the base excision repair (BER) of DNA lesions as well as in the regulation of gene expression of different transcription factors. The translocation of APE1/ Ref- 1 from the cytoplasm into the nucleus is activated upon ROS exposure in different cell types. Several studies indicated an important role for NADPH oxidase in the generation of intracellular ROS. The treatment of non-phagocytic cells with $10 \mu \mathrm{M} \mathrm{DPI}$ for 10 minutes prevented the translocation of APE1/Ref-1 completely (17). In physiological conditions, NADPH oxidase has a low level of activity $(18,19)$. The addition of DPI to untreated keratinocytes most likely lead to the inhibition of BER, therefore the endogenous damage will not be repaired anymore and lead to a detectable induction of DNA damage (figure 4). 


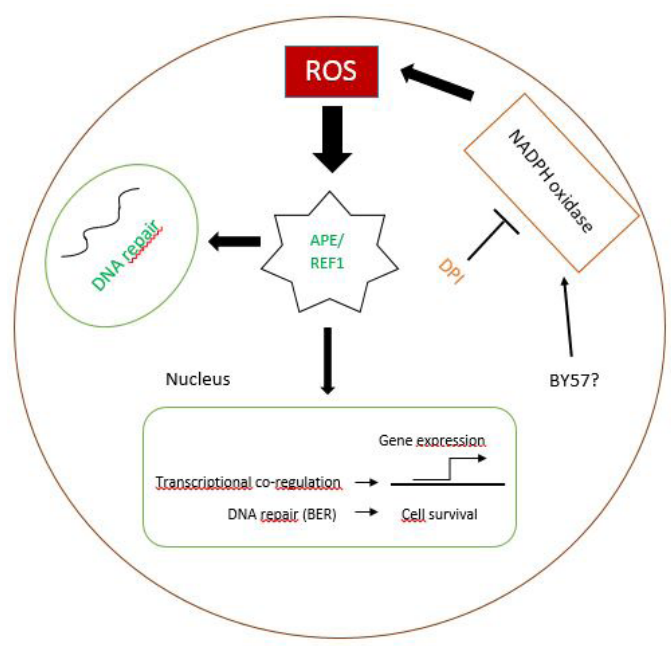

Figure 4. Schematic overview of the potential mechanism of BER inhibition. The translocation of APE1/Ref-1 from the cytoplasm into the nucleus is activated upon ROS generated by NADPH oxidase. DPI, an NADPH oxidase inhibitor, is able to inhibit NADPH oxidase and therefore the translocation of APE1/Ref- 1 into the nucleus will be prevented. BY 57 is a potential stimulator of ROS generated by NADPH oxidases (17). Addition of DPI will prevent the potential stimulation of NADPH oxidase by BY 57 . The effect of BY 57 is not confirmed yet and is therefore indicated with a question mark.

As mentioned above, $\mathrm{BY}_{57}$ in combination with both concentrations DPI lead to an induction of DNA fragmentation probably caused via DPI instead of an additional effect of BY 57 . Since DPI inhibits ROS generated by NADPH oxidase, these findings may indicate that BY 57 could potentially stimulate NADPH oxidase which could induce DNA fragmentation via the production of ROS. In this case, DPI will inhibit the DNA damage inducing effects of BY 57 via the inhibition of NADPH oxidase.

However, the addition of a DNA repair inhibitor, hydroxyurea (HU), to control keratinocytes increased the formation of DNA strand breaks (figure 3). It was expected that the addition of $\mathrm{HU}$ in combination with $\mathrm{BY}_{57}$ will lead to an additional induction of DNA fragmentation, since $\mathrm{BY}_{57}$ itself caused increased DNA damaging levels. In contrast, the levels of DNA fragmentation in the combination treatment (BY57 plus $\mathrm{HU}$ ) seem to be equal to the level of DNA fragmentation caused by the addition of $\mathrm{HU}$ to the control skin cells (figure 3). This is an unexpected finding and could not be explained by the present results and available literature. No conclusion could be drawn from the DNA damaging effects of the combination $\mathrm{BY}_{57}$ with $\mathrm{HU}$ due to the high variations between replicates of 
this combination treatment. Another remarkable finding is the higher induction of DNA fragmentation by $50 \mu \mathrm{M}$ DPI compared to the DNA fragmentation level caused by the addition of $\mathrm{HU}$ to the control keratinocytes (figure 3), this suggest that DPI may act via additional mechanisms.

Finally, in the present discussion two DNA repair inhibition mechanisms, APE1/Ref-1 and hydroxyurea, were mentioned. It is important to notice that both potential inhibitions lead to an induction of DNA strand breaks in the comet assay in contrast to the function of endonucleases. During base excision repair (BER), apurinic/apyrimidic (AP) sites are created to remove the damaged part of the DNA. Endonucleases are also involved in BER and are enzymes that cleave the phosphodiester bond within a DNA strand that causes more DNA breaks. Normally, the inhibition of an endonuclease will lead to less breakages. However, this is not the case in the comet assay, since the high $\mathrm{pH}$ value of the electrophoresis buffer $(\mathrm{pH}>12)$ during the electrophoresis still creates a breakage into the DNA.

\section{Conclusion}

The aim of this study was to investigate the DNA damaging effects of $\mathrm{BY}_{57}$ in combination with hydrogen peroxide and resorcinol in human keratinocyte ( $\mathrm{HaCaT}$ ) cells. Furthermore, another aim of the present study was to evaluate the potential DNA damaging mechanisms caused by these hair dye components. To conclude, the exposure of human keratinocytes to Basic Yellow 57, hydrogen peroxide and the combination treatments of the hair dye components containing hydrogen peroxide lead to an induction of DNA fragmentation. However, the possible working mechanism of DNA damaging effects caused by BY 57 remains unclear. The DNA damaging effects of DPI could suggest an inhibition of the DNA repair system via the inhibition of NADPH oxidase. Since this effect is not confirmed by the results of the DNA repair inhibitor $(\mathrm{HU})$, no conclusion could be drawn from these findings. To elucidate the possible DNA damaging mechanisms of BY 57 on human keratinocytes, further research is needed.

\section{Role of the student}

C. van Gorp was an undergraduate student in Biomedical Sciences working under the supervision of G.J. Hageman when the research in this report was performed. The topic was proposed by the supervisor. The Comet assay, the processing of the results as well formulation of the conclusion and the writing were done by the student. 


\section{References}

1. National Cancer Institute (NCI). Hair Dyes and Cancer Risk 2011. Available from: http://www.cancer.gov/ cancertopics/factsheet/Risk/hair-dyes\#r1.

2. American Cancer Society. Hair Dyes 2011. Available from: http://www.cancer.org/cancer/cancercauses/ othercarcinogens/intheworkplace/hair-dyes.

3. Czene K, Tiikkaja S, Hemminki K. Cancer risks in hairdressers: assessment of carcinogenicity of hair dyes and gels. International journal of cancer. 2003;105(1):108-12.

4. SCCS. Opinion on Basic Yellow 57. Colipia $n^{\circ}$ C10. Directorate-General for Health \& Consumers. 2010.

5. SCCS. Opinion of the scientific committee on cosmetic products and non-food products intended for consumers concerning basic yellow 57 . Colipia $n^{\circ} \mathrm{C} 10.2003$.

6. Veal EA, Day AM, Morgan BA. Hydrogen peroxide sensing and signaling. Molecular cell. 2007;26(1):1-14.

7. Re-evaluation of Some Organic Chemicals, Hydrazine and Hydrogen Peroxide: World Health Organization International Agency For Research On Cancer; 1999.

8. SCCS. Hair dyes and hydrogen peroxide. 2011.

9. Public Health England. Hydrogen Peroxide: General Information. Toxicology Department. 2009.

10. Hahn S, Kielhorn J, Koppenhöfer J, Wibbertmann A, Mangelsdorf I. Concise International Chemical Assessment Document 71: Resorcinol. World Health Organization. 2006.

11. PubChem Compound. Compund Summary: Resorcinol. Pharmacology and Biomedical Effects and Toxicology: NCBI; [cited 2009]. Available from: https://pubchem.ncbi.nlm.nih.gov/summary/summary. cgi?cid=5054\&loc=ec_rcs\#x395.

12. SCCS. Opinion on Resorcinol. Colipa $n^{\circ}$ A11. 2010.

13. Li Y, Trush MA. Diphenyleneiodonium, an NAD (P) H oxidase inhibitor, also potently inhibits mitochondrial reactive oxygen species production. Biochemical and biophysical research communications. 1998;253(2):295-9.

14. Day III RS. Deoxyguanosine reverses inhibition by hydroxyurea of repair of UV-irradiated adenovirus 5. Mutation Research/DNA Repair. 1993;293(3):215-23.

15. Mercken EM, Hageman GJ, Schols AM, Akkermans MA, Bast A, Wouters EF. Rehabilitation decreases exerciseinduced oxidative stress in chronic obstructive pulmonary disease. American journal of respiratory and critical care medicine. 2005;172(8):994-1001.

16. Lambert AJ, Buckingham JA, Boysen HM, Brand MD. Diphenyleneiodonium acutely inhibits reactive oxygen species production by mitochondrial complex I during reverse, but not forward electron transport. Biochimica et Biophysica Acta (BBA)-Bioenergetics. 2008;1777(5):397-403.

17. Pines A, Perrone L, Bivi N, Romanello M, Damante G, Gulisano M, et al. Activation of APE1/Ref-1 is dependent on reactive oxygen species generated after purinergic receptor stimulation by ATP. Nucleic acids research. 2005;33(14):4379-94.

18. Riganti C, Gazzano E, Polimeni M, Costamagna C, Bosia A, Ghigo D. Diphenyleneiodonium inhibits the cell redox metabolism and induces oxidative stress. Journal of Biological Chemistry. 2004;279(46):47726-31.

19. Li J-M, Shah AM. ROS generation by nonphagocytic NADPH oxidase: potential relevance in diabetic nephropathy. Journal of the American Society of Nephrology. 2003;14(suppl 3):S221-S6. 